\title{
Investigate Students' Attitudes toward Computer Based Test (CBT) at Chemistry Course
}

\author{
Amnah Hassan Dammas \\ Department of Education Management and Developing - Females \\ Ministry of Education - Jeddah- Saudia Arabia
}

\begin{abstract}
Computer Based Assessment (CBT) is being a highly widespread method to assess students' fulfillment at the university level. This study seeks to examine the attitude of the students towards computer-based test (CBT) at the KAU Saudi Arabia Jeddah. Quantitative approach using survey questionnaire was adopted to carry out the current study using convenience-sampling technique. The sample consists of (60) undergraduate students who had taken the exam on CBT were selected from college of science - chemistry department to examine their perceptions towards CBT. To achieve this aim, the researchers examine the possibility of using student feedback in the effectiveness of this method in assessment. The findings show that: the majority of respondents have positive attitude towards CBT, $(83.7 \%)$ of students said they were competent with the use of computer due to their prior experience. Regarding test administration, they reported that there are some errors in the chemical equations, formulas, construction in the exam sections, and inadequate time. Nevertheless, they achieved the exam successfully and reached satisfaction through CBT features such as direct scoring, validity, and transparency in grading. The bottom line, CBT experience will become favorable for students and then will earn its effectiveness in the context of assessments methods.
\end{abstract}

KEYWORDS: Computer Based Test (CBT), Chemistry course, Undergraduate Students, computer experience.

\section{INTRODUCTION}

Over the past four decades, there has been gradual evolution in computer-based testing (CBT) as a viable alternative to paper-and-pencil testing (PPT). However, the transformation to CBT is neither simple nor cheap. Student assessment is a quite fundamental factor in every learning paradigm. Teachers' evaluate students and learning outcomes to direct and encourage them according to their fulfillment (1).It is mostly known that examinations determines the extent to which educational goals have been accomplished as well as the extent to which educational institutions have served the needs of society (2).Examinations are not only limited to measure educational needs or societal objectives but also incorporate in a way of coping with the educational system (3).

According to Rehmani (2003) examinations play an important role in determining what goes on in the classroom in terms of what, and how teachers teach and students learn and can have effect on both teaching and learning' (4). Several examination modes utilized in higher education institutions to assess academic progress, for instance, paper-pencil-based examinations, assignments, presentations. Sim, Holifield, \& Brown (2004) identified more than fifty different techniques used within higher education for assessment purposes; the most commonly used are examinations (5). 
The rapid advancement of Information and Communication Technologies (ICT) in teaching and learning has shifted the paradigm (6) from paper-pencil-based to computer-based system of examinations which are usually termed as Computer Assisted Testing, Computerized Assessment, Computer Based Testing (CBT), Computer Aided Assessment (CAA), Computer Based Assessment (CBA), Online Assessment, E-Assessment and Web-Based assessment [ (7); (8)].

Computer - based tests (CBT) are the form of assessment in which the computer is an integral part of question papers' delivery, response storage, marking of response or reporting of results from a test or exercise (9). Conole and Warburton (2005) defined CBT as 'the use of computers for assessing students' learning' (10). It is required to think, re-consider, and modify or change the traditional test manners. Electronic assessment tools had reduced the load of teachers and facilitate exams execution purposefully because of inclusion of ICTs in education. CBTs can be applied to promote further efficient learning by examining students' knowledge and understanding in many fields such as chemistry courses.

Students' prior experience in computer and communication skills is essential matters in CBTs.CBT are a method that may does not suit the learning styles of many students. The primary factor in determining whether an assessment program is beneficial or not depends on whether the assessment tasks are relevant to the purposes and learning outcomes for the course, not forgetting the attitudes and skills that are to be examined. For this, we will try in this study to investigate students' perceptions and their attitudes towards this kind of exams, and to identify the technical and scientific issues that they face. Computer and related technologies provides a powerful tools to encounter the challenges of designing and implementing assessments modes that go beyond the conventional practices and facilitate accessing a widely sources of information, cognitive skills and knowledge.

Computer based assessment technique is becoming more and more widespread in HEIs. According to Conole and Warburton (2005): "CBTs are written to test specific levels of ability they have the potential to deliver more accurate and reliable results than traditional exams" (10). Traditional methods of assessment are being changed by automated assessment in all over the world progressively but it is not clear so far to up to what extent these changes will be fruitful to the academicians and administrators of HEIs, in addition to that, institutions across the globe are migrating toward the use of (CBT) to test students' knowledge (11).

Therefore, it was significantly important to perceive university students' perceptions towards Computer-Based examinations. It was noticed through literature that little interest was paid to understand students' thoughts about CBTs in terms of their attitudes in terms of their role in assessing the responses of students taking CBT in chemistry course. Authors of this research, thus, analyzed students' attitude in different dimensions, i.e., gender, age, academic level, academic performance, and prior experience in computer, computer anxiety, and constraints on the utilizing of CBT. The present study aims to identify the attitudes of those level students towards CBT and analyze their perceptions in terms of the above dimensions.

The paper is organized as follows. In Section (2), a brief literature review that summarizes the studies of those authors who experimented or surveyed CBT in different courses at HEIs. Section (3), a review of theoretical background of CBT is presented. Section (4) explains the importance of the study. Study problem is presented in Section (5). In Section (6), Purpose of the study is determined. In Section (7), Study questions were addressed. Section (8), explains the research methodology. In section (9), data analysis and discussion of results are shown. 
Finally, conclusion, study limitations, and future studies were included in Section (10), section (11), and section (12) respectively.

\section{PREVIOUS STUDIES}

(Powers \& O'Neill, 2006), assessed the degree of contribution of CBT to performance among a number of students of mathematics by using a questionnaire survey. It was found that no serious effect (12). Karadeniz (2009) studied the impact of CBT and PPT and mobile-based test on students' performance. A group of 38 students was experimented for 3 weeks. Significant differences were found between the scores achieved by the students in second week, but not in first week. It was perceived by the authors that students had positive attitude towards CBT and assessment due to ease of use, comprehensive and instant feedback. Moreover, most favored the CBT and the least favored were the PPTs (13).

The National University of Singapore introduced computer-based testing (CBT) in 2004. Lim, et al (2006) examined medical students' attitude about CBT VS PBT testing. Through an online survey 213 (53.5\%) final-year students were tested out of which 91 (79.8\%) preferred CBT, 11 (9.6\%) preferred PPT format and 12 (10.5\%) were un-sure. Authors further explained that 42 indicated that 42 liked CBT because of good quality of images and independent of assigned seating positions; 22 liked because they could proceed at their own pace; one stated that CBT examinations was fun; 4 enjoyed the convenience of CBT and 6 cited "equality" as the reason they preferred CBT over PPT

The major factors leading to difficulties in CBT applications under two titles, as factors resulting from "users" and "technology used". He states that the user's gender, the ability to process information, the ability to use a computer, and the level of anxiety could have an influence on an application (14).

Many researchers have already done studies investigating the relationship between computer usage ability and achievement tests. Yurdabakan (2012) (15) identifies some of these studies [ (16); (17); (18)] stressing that computer usage ability is an important predictor of respondent achievement; therefore, those poor students at computers may show low achievement in CBT. However, they added that with the increase in computer technologies and access opportunities, such problems might decrease.

In some of the studies investigating the difference between assessment methods in terms of gender, race and age, such as (19), no significant difference was found in achievements, whereas in some other studies (20) little significant difference was observed. In their recent study, Terzis and Economides (2011) describe the trends of male and female students towards CBT (21). Yurdabakan (2011) reported that as a result, they highlighted both genders having positive views on CBTs, if they are based on games; they are open and course-related (15). Additionally, they state that the attitudes of males and females towards CBTs are under the influence of social environment; the boys focus on the usefulness while the girls stress the ease of use.

Study of ( Williams ,2007) he examined attitudes of pre - hospital undergraduate students undertaking a web based examination as an adjunct to the traditional paper based examination mode using questionnaire survey among (94) students, the study found students' satisfaction and performance is high (22).

(Ozden et al. 2004), in his study "students' perception of on line assessment". Questionnaire and interview among (46) students were utilized. The findings indicated that students' 
perceived as an effective testing mode (23). Using content analysis, (Johnson et al .2004), examined the relationship between assessment mode and students' perception. The results shows that computer based questions seems to be harder than if it were to be in paper based questions (24) . (Russell et al.2003) the purpose of the study is" investigated reasons behind low performance in CBT" .By using a survey, he concluded that the low performance can be attributed to inability to practice / review old exams / questions (25).

(McVay, 2002) "Examined disparity in students' performance between CBT and PPT testing modes". By Using compares performance of the same students using the two modes as a research method, the findings of this study indicated that disparity exists (26). A study was conducted by (Millsap, 2000) to investigate likely disparity between the two testing modes among (585) military recruits. Content analysis method was used. It was found that the testing method did not affect the results (27).

\section{STUDY BACKGROUND}

Because of growing number of teachers and students who use computer technologies in classrooms to support or execute the instructions, it is expected that the schools and HEIs will shift the technology use in assessment also. Computer-based tests (CBT) contain assessments that are carried out using the computer, either over computer program or over a web-based system. Already, many assessments have been switched into a computerized format, including summative, large scale, and daily formative assessments (28).Increased student motivate, enhanced reliability in data gathering, and quick reporting of results are some of the evident advantages to CBTs [ (29); (30)].

Information and Communication Technologies (ICTs) have been advanced rapidly and widespread, utilized for different purposes, and used intensively in schools and higher education institutions (HEIs) in several sides like students' assessment and e - learning as well. CBT systems are carried out by using the tools of ICTs and its applications. A CBT system is seen as a very significant instrument to assess students' knowledge at particular stage and to assist learners in identifying the gap between requested criteria and the actual standard for them.

Studies have also found that students enjoy taking CBTs and are motivated by the use of technology [ (31); (32)]. Accessibility features can be conveniently embedded into CBTs, allowing for supports and accommodations such as glossaries, color contrast, text-to-speech, spell check, highlighting, and Closed-captioning (18) .The quick reporting of results is particularly useful to educators as they are able to access and use these results to make timely changes in instruction if necessary [ (18); (33); (30)]. CBTs can easily administer exam timing, and ensuring that all students are given the same amount of time to accomplish the exam. CBTs can also permit students to have access to the same support tools, including calculators, dictionaries, and only let the use of those tools when it is suitable (31).

In addition, the benefits of CBT ensure easier administration; bring down printing costs and paperless distribution, increased exam security, fast feedback, and integrated support instruments (34). With all of these benefits, it is easy to see why many HEIs and high schools are employing the use of technology for assessments. As CBT launched to be utilized for summative assessment, investigating students' attitudes towards CBTs became significant. From students' perspective of the CBT, there have been a number of mixed responses. Previous literatures presented that more individuals expected problems with the computer supported assessment than really had them (35). 
Despite few students being confident about CBT before completing the assessment, more students stated a preference for CBT thereafter, previous study conducted indicated a preference for CBT over PPT (36).Some studies reported the main disadvantage as being increased anxiety amongst those unfamiliar with use of computer[ (35); (36)] and as such students agreed that they are "technophobic".

The major challenges to test examinees through computers demand a proper software designing. To confirm this request, students' attitudes and perceptions on the advantages and disadvantages of a computerized test are significant, as the user, perceptions and his opinions are critical in the approval, application, and advancement in computerized tests. Moreover, while recognizing the system level usefulness that associated with CBT it is significant to generally, different fields are worthy to investigate in this area, including problems concerning the factors that may affect performance and student perceptions regarding the CBTs.

These evolutions in computers and ICTs have affected several fields including educational assessment and examinations and significantly reshaped the manner of assessment and exams mode. This has led to the development of (CBTs), and/or computerized adaptive test applications, besides those traditional paper-pencil tests (PPTs).In many academic fields, educational measurement has been moving towards the utilizing of CBTs, which defined as exams or assessments that are Managed by computer in either stand-alone or dedicated network or by other technology devices linked to the internet or World Wide Web (www) most of them using multiple-choice questions (37).

There are two main types of assessments systems: Paper Based Test (PBT) and Computer Based Test (CBT) (1).Due to the popularity of ICTs, many schools and institutions replacing the traditional paper and pen assessment for learners. Students prefer CBT instead of PBT as they think that CBT would be interactive, exciting, accurate, secure, credible, and smooth (38).Also, several competitive advantages that CBT has such as less cost, more security, and high accuracy. Furthermore, it minimizes the required efforts to accomplish tasks, and time for test preparation, marking, scheduling, recording and analyzing the results [(1); (39)].

At present, in the Saudi universities the most applied evaluation of students' knowledge is traditional method that is a combination of essay and practical tests. Nevertheless, in the past few years, the number of students increased significantly, the traditional examination method consumes a long time for evaluation and assessment. An automated testing system is the solution of examination for large classes to address these problems and other issues.

As now computer-based tests are launched to be applied especially at primary and secondary education level, for such reasons like: their exam results are scored immediately and reported in detail, their applications are effective and reliable, flexible, they reduce the costs for longterm, make the integration of audio-visual materials is possible, and enable the rater to easily adjust the student response time compared to traditional PPT (40).

Therefore, the actuality that students' perception of CBT for chemistry courses is under investigation subject. This study describes results in this field with a view to expand better practice, guidelines, and models of application and valuation of a specific kind of exam mode, namely CBT for undergraduate chemistry courses. Examine the relationship between assessment method and the behavior of the students being assessed. 
Finally, CBT is being a major part of e - learning and assessment systems in HEIs and schools alike.

Therefore, it is very important to investigate the factors that affect the students' attitude toward using CBT in order to implement CBT systems successfully. The aim of this research is to examine the factors that influence the students' attitude toward using CBT system in Saudi.

\section{IMPORTANCE OF THE STUDY}

Computer Based test (CBT) is being a very popular method to evaluate students' performance at the university level. Even though mode effects of different formats of assessments have been conducted for decades, it is important to continue the line of research. As the availability of technology in classrooms increases, and as teachers and students become more technologically wit, it is fundamental that they understand how transforming from paper-based to computerbased tests may have an impact on student perceptions and their performance. This is of particular importance when teachers have the capacity to produce their own computer-based texts of assessments that are used between students and classrooms and are applied to make instructional decisions.

This study also evaluates the responses of students taking CBT. These issues and others worth a consideration such as students' attitudes towards computerized testing may promote or impede the testing process. Therefore, it is essential for us to be aware of the accompanying affective impacts of CBTs, which is still not understood yet. The attitudes that students have, are an important factor in whether CBT programs become an efficient part of the curriculum of schools and HEIS alike. Awareness of what attitudes students' hold can help educators in curriculum designing in evaluating the role of computers and prior experience in CBTs, and in the future local development of a curriculum that incorporates the computers usage.

This study also contribute to the existing knowledge about the relative contributions of previous computer - related experience on computerized testing performance as well as on examinees attitudes and acceptance the use of computers in testing. Furthermore, a study such as this will hopefully assist in the evaluation of CBTs, in order to minimize factors that may inhibit optimal achievement performance. If CBT is well accepted by students, and with constantly improvements being made in the design of software, it may become an obtainable mode of assessment in our schools and universities better.

\section{STUDY PROBLEM}

Investigating students' perceptions and attitudes towards CBTs is not an easy matter. According to their personal abilities scientific or technical, so there are many different views on this issue. Some of the examinees through computerized tests notified that it is more difficult for them to navigate back to rework problems. Others are reluctant to the computerized testing method simply because they are accustomed to take notes, writing comments, and circling question and/or answers for later review (41). Others said that they read more easily and quickly on paper than on a computer screen.

While the computer crashes are rare to happen, but it is expected to occur through the exam time, this can void the efforts of examinees [ (18); (33)].

Students' attitudes about performance grades, exam appropriateness, validity control, and computer anxiety are generally the points of concern. Some test takers have a general anxiety about the computer itself, while others are more worried about whether their level of computer experience 
(42). All these conflicting attitudes serve as the reasonable grounds for this study.

Use of the mouse, screen visibility, screen size, screen resolution, font size, display rate, and Scrolling are some technical issues in CBT that affect students' response to the designed chemistry questions according to (Jimoh et al.2012), also presentation graphics and the User interface layout has been known to affect examinees as they may have difficulty with particular aspects of it , or they may object to specific element of adaptive exam delivery (43).Therefore, it is anticipated that providing certain information about students' perceptions about CBTs in undergraduate chemistry course might enable the stakeholders to make improvements of the current use of CBT system. These issues and others are captured in the survey questionnaire tool of the current study.

\section{PURPOSE OF THE STUDY}

The main objective of this study is to" investigate students' perception towards CBT for testing Undergraduate chemistry courses in Saudi Arabia". It also supports exploring the factors suits CBT in Saudi HEIs. In addition, here are some more objectives related to the statement of this research.

1. Identifying the overall constraints on the utilizing of CBT for the chemistry courses?

2. Explaining the factors that influence students' attitudes to assessment method?

3. Examining the relationship between prior computer experience and performance in CBT?

\section{STUDY QUESTIONS}

To address the problems specified in this study, three sub questions were addressed as follows:

1. QUESTION ONE (Q1): What are the overall limitations on the utilizing of CBT for chemistry Courses?

2. QUESTION TWO (Q2): What are the factors that affect students' attitudes to assessment Method?

3. QUESTION THREE (Q3): What is the relationship between prior computer experience and Performance in CBT?

\section{METHODOLOGY}

Many previous studies were reviewed, it is obvious that quantitative approach using survey Questionnaire is most suitable process of examining students' perception about CBT [ (22); (44) (23)].Accordingly, the researchers will use the same methodology for the current search using a questionnaire developed for this purpose. A five-point Likert-type scale of agreement running from ( 1 = Strongly Disagree, $2=$ Disagree, $3=$ Uncertain, $4=$ Agree and $5=$ Strongly Agree ) were adopted. Before the questionnaire was conducted, it was pretested on ten students in order to measure the construct validity of the perception measurement. Furthermore, the questionnaire was validated through a number of specialists in this field, there comments were considered in the final version.

\section{Studfy Population}

The target population for the current study includes all undergraduate students in chemistry department at King Abdul-Aziz University (KAU) - college of Science, Jeddah City. 


\section{Study Sample}

In the sampling technique, the study is based on a convenience sample of (60) undergraduate students who taught chemistry science in KAU, from May - October 2016. (60) Questionnaires were distributed randomly in the university main campus in Jeddah city, (54) questionnaires were collected; five of those were discarded because they were incomplete. (49) found usable for this study. The Tables (1), (2), (3), (4) and (5), show the distribution of demographic characteristics of the sample.

Table (1): Respondents' profile according to their Sex

\begin{tabular}{|lll|}
\hline Respondent Sex & Frequency & Percentage (\%) \\
\hline Male & 31 & 63.3 \\
\hline Female & 18 & 36.7 \\
\hline Total & 49 & $100 \%$ \\
\hline
\end{tabular}

Table (1) indicated that out of (49) respondents, (31) were male with percent (63.3\%) while (19) were female with percent (36.7\%).

Table (2): Respondents' Respondents' profile according to their Age

\begin{tabular}{|lll|}
\hline Respondent's Age & Frequency & Percentage (\%) \\
\hline Less than 19 years & 7 & 14.286 \\
\hline $19-21$ years & 18 & 36.735 \\
\hline $22-24$ years & 16 & 32.653 \\
\hline $25-27$ years & 8 & 16.326 \\
\hline Total & 49 & $100 \%$ \\
\hline
\end{tabular}

Table (2): The sample shows that: (7) student with percent (14.286 \%) were less than (19) years, (18) students with percent (36. $735 \%)$ aged between (19-21) years, (16) students with percent (32.653\%) aged between (22-26) years, while (8) students with percent (16.326 \%) aged between $(25-27)$ years. Also, illustrates that the respondents is highly controlled by the age groups of (19-21) years and (22-24) years as well. These figures show that an age group of respondents from the average age group of students. This indicates that the mark gained in the CBT is accurate, and students' cognitive capacity has improved.

Table (3): Respondents' profile according to their academic performance

\begin{tabular}{|lll|}
\hline Academic Performance & Frequency & Percentage ( \% ) \\
\hline Excellent & 9 & 18.367 \\
\hline Very Good & 25 & $\mathbf{5 1 . 0 2 0}$ \\
\hline Good & 13 & $\mathbf{2 6 . 5 3 1}$ \\
\hline No response & 02 & 4.082 \\
\hline Total & 49 & 100 \\
\hline
\end{tabular}

The sample study appears that (9) students with percent (18.367\%) were academically excellent, (25) of them with percentage (51.020 \%) were very good academically, (13) students with percentage (26.531\%) were academically good, while (2) students with percentage $(4.082 \%)$ did not reply. The table also presents that a significant percentage of respondents are performing either very good or good academically. Low or high trend in the results obtained by some students in a CBT can be attributed to external factors or examinee himself. In general, as results show the majority of respondents have high attitude towards the adoption of CBT.

Table (4): Respondents' level of prior experience and familiarity in computer

\section{Respondents Scales}

in computer experience

Male Female Together

Frequency Percentage Frequency Percentage Frequency Percentage 
Dammas, A.H. (2016). Investigate Students' Attitudes towards Computer Based Test (CBT) at Chemistry Course. Archives of Business Research, 4(6), 58-71.

\begin{tabular}{|lllllll|}
\hline High & 15 & $\mathbf{4 8 . 3 8 7}$ & $\mathbf{9}$ & $\mathbf{0 . 5 0 0 0}$ & $\mathbf{2 4}$ & $\mathbf{4 8 . 9 8 0}$ \\
\hline Average & 11 & $\mathbf{3 5 . 4 8 4}$ & $\mathbf{6}$ & $\mathbf{3 3 . 3 3 3}$ & $\mathbf{1 7}$ & $\mathbf{3 4 . 6 9 4}$ \\
\hline Low & $\mathbf{5}$ & $\mathbf{1 6 . 1 2 9}$ & $\mathbf{3}$ & $\mathbf{1 6 . 6 6 7}$ & $\mathbf{0 8}$ & $\mathbf{1 6 . 3 2 6}$ \\
\hline Total & 31 & & 18 & $\mathbf{1 0 0 \%}$ & $\mathbf{4 9}$ & $\mathbf{1 0 0 \%}$ \\
\hline
\end{tabular}

The study sample indicated that (24) students with percentage (48.98\%) together (male and female)

Responded that they own high computer experience. (17) Student with percentage (34.694\%) said that their computer experience is average, while only (8) students with percentage ( $16.326 \%$ ) admitted a low experience in computer. Findings also illustrated in the above table that the majority of them have a high experience in the computer. By considering the efficacy of the prior experience in computer on the performance of students out of their CBT, system in the university is insignificant; as such, students without any problems will achieve tasks easily.

Table (5): Respondents' profile according to their academic level

\begin{tabular}{|lll|}
\hline Level of Study & Frequency & Percentage $(\%)$ \\
\hline $1^{\text {st }}$.year & 4 & 8.163 \\
\hline $2^{\text {II }}$.year & 16 & 32.653 \\
\hline $3^{\text {Iu }}$.year & 18 & 36.735 \\
\hline $4^{\text {III }}$.year & 11 & 22.449 \\
\hline Total & 49 & $100 \%$ \\
\hline
\end{tabular}

The table shows that majority of respondents have spent two academic semesters at least in the university. (4) students with percentage ( $8.163 \%$ ) are in the 1st.year , (16) students with percentage ( $32.653 \%$ ) are in the 2nd.year , ( 18 ) students with percentage ( $36.753 \%$ ) are in their 3rd. year, while (11) students with percentage ( $22.449 \%$ ) are in 4th.year. This shows those students' responses to questions will considered well aware having spent more than one academic semester in the university, this also indicates that they have taken the CBT exams many times. Overwhelming percentage of the respondents fall within the level of $2 \mathrm{nd}$. Year and 3rd.year, which means they accepted to have the CBT in their academic courses in general.

\section{Study Questions Analysis}

\section{DATA ANALYSIS AND DISCUSSION OF RESULTS}

\section{the 1st . study question (q1)}

What are the overall limitations on the utilizing of CBT for chemistry courses?

The aim of the first question is identify the most common constraints that associated with CBT for chemistry courses. To answer the question, respondents were asked about the constraints that faced them when they use the CBT for chemistry course examining. Table (6) shows the findings in frequencies \& percentages. 
Table (6): Limitations on the usage CBT in chemistry courses.

\begin{tabular}{|l|c|c|}
\hline Constraint & Frequency & Percentage ( \% ) \\
\hline System Security & 5 & 10.204 \\
\hline Software access & 4 & $\mathbf{8 . 1 6 3}$ \\
\hline Answers Submitting & 13 & $\mathbf{2 6 . 5 3 1}$ \\
\hline Log in Problem & 5 & 10.204 \\
\hline Answers Editing & 7 & $\mathbf{1 4 . 2 8 6}$ \\
\hline Do not have any of above problems. & 15 & $\mathbf{3 0 . 6 1 2}$ \\
\hline Total & 49 & $\mathbf{1 0 0 \%}$ \\
\hline
\end{tabular}

Table (6), indicates that (30.612\%) of students do not have any of above listed issues. $(26.531 \%)$ of them said they had problems in their answers Submitting. (14.286\%) faced problems in their answers editing. (10.204\%) encountered difficulties in system security, followed by (8.163\%) had issues with logging on to their portal.

\section{THE 2nd. STUDY QUESTION (Q2)}

What are the factors that influence students' attitudes to assessment mode?

Ranking students' attitudes towards the CBT test to understand the prime issues concerning CBT is the aim of this question. To answer the above question, respondents were asked with several scales on the administration of computerized test. A five-point Likert-type scale of agreement running from ( $1=$ Strongly Disagree, $2=$ Disagree, $3=$ Uncertain, $4=$ Agree and $5=$ Strongly Agree) were adopted as shown in Table (7).

Table (7): Respondents' attitudes toward CBT

\begin{tabular}{|l|l|l|l|l|l|l|l|}
\hline Item & $\mathbf{1}$ & $\mathbf{2}$ & $\mathbf{3}$ & $\mathbf{4}$ & $\mathbf{5}$ & $\begin{array}{c}\text { Tota } \\
\mathbf{1}\end{array}$ & Mean \\
\hline CBT was very efficient & 4 & 17 & 20 & 78 & 29 & 148 & 3.02 \\
\hline CBT provides me a positive experience & 5 & 12 & 22 & 90 & 27 & 156 & 3.18 \\
\hline The CBT causes me a concern & 3 & 24 & 47 & 33 & 32 & 139 & 2.83 \\
\hline $\begin{array}{l}\text { CBT exam was conducted in a helpful environment for } \\
\text { Examinees. }\end{array}$ & 2 & 9 & 7 & 50 & 130 & 198 & 4.04 \\
\hline CBT is better than PPT & 10 & 27 & 44 & 9 & 21 & 111 & 2.26 \\
\hline I prefer CBT compared with PPT & 11 & 31 & 40 & 18 & 24 & 124 & 2.53 \\
\hline I believe that CBT ensured justice and equity. & 13 & 18 & 27 & 30 & 41 & 129 & 2.63 \\
\hline $\begin{array}{l}\text { I prefer receiving my exams results automatically utilizing } \\
\text { the CBT system }\end{array}$ & 3 & 15 & 14 & 61 & 83 & 174 & 3.55 \\
\hline
\end{tabular}

Results in the above table shows that from the respondents' perspective, the most widespread status with the CBT management is the success it made in the item "CBT exam was conducted in a helpful environment for examinees" with mean of (4.04), followed by the item "I prefer receiving my exams results automatically utilizing the CBT system" has been specified to be the following utmost important item with Mean (3.55), this means that CBT has attracted the majority of examinees' awareness and seen as a positive attitude.

As specified by examinees, they admitted in the item "CBT provides me a positive experience" with mean (3.18).The item "CBT was very efficient" came after with its mean of (3.02). Respondents did not agree on the item "CBT is better than PPT" as it has the minimum mean of (2.26).

\section{THE 3rd. STUDY QUESTION (Q3)}

What is the relationship between prior computer experience and performance in CBT? 
To answer the above question, respondents were asked if they feel prior computer experience has effect on their test score. The response was on a five-point Likert Scale. The responses are presented below in table (8).

Table (8): Respondents' opinion on the impact of prior computer experience on performance.

\begin{tabular}{|c|c|c|c|c|c|c|c|c|c|c|c|}
\hline My previous & & 1 & 2 & 3 & 4 & & & 5 & Total & Mean & S.D \\
\hline experience in & & & $\mathrm{n}$ & & & $\%$ & $\mathrm{n}$ & $\%$ & & & \\
\hline $\begin{array}{l}\text { computer } \\
\text { influence } \\
\text { on my } \\
\text { performance }\end{array}$ & 5 & 10.204 & \begin{tabular}{l|l}
6 & 12.245 \\
\end{tabular} & \begin{tabular}{l|l|}
7 & 14.286 \\
\end{tabular} & 23 & 46.938 & 8 & 16.327 & $49(100)$ & 3.199 & 1.249 \\
\hline
\end{tabular}

From the above Table above (46.938 \%) of students agree that " previous experience in computer influences their performance (test score) ", (16.327\%) of respondent were strongly agree, (14.286\%) of respondents were uncertain, $(12.245 \%)$ disagreed and only $(10.204 \%)$ strongly disagreed with this statement.

\section{CONCLUSION}

From this study, it has been observed that students' in general are becoming more interested in the use new method of assessment, which is the CBT. Therefore, CBT should be initiated in all levels of educational assessment in HEIs and schools alike.

The result likewise show that the helpful environment provided by the system and receiving results automatically using the CBT system is an advantage of the new system. It is concluded that there is an urgent need for basic training on the use of computer before exposure to CBT mode of assessment to enhance the students' attitude towards computer-based exams, and remove the concerns they have relating to their final grades.

Regarding the questions of chemistry exam, the findings of this study revealed that, inadequate test time and mistaken questions were among major reason of students' failure with CBT mode of assessment due to the nature of undergraduate chemistry courses. It is recommended that the exam questions should be free of errors and students have enough time to answer the examination.

\section{STUDY LIMITATIONS}

Three limitations have been specified for this study. [1] Lack of Arab studies in this area; [2] All students were already familiar with the PPT format; the CBT format was new for all most all students particularly in scientific courses such as chemistry. Giving students adequate training (demo exam) will push them for more confident, eliminate computer anxiety, and enhance performance and attitudes towards the CBT as well; and [3] the time and sample size. This study was carried out through summer semester 2016; therefore, the results cannot be generalized.

\section{FUTURE STUDIES}

The results of the current study add to the literature basis concerning attitudes towards CBT. Accordingly, it is necessary to investigate the use of computer-based classroom assessments, which is lacking in the existing literature. integrated administration and timing easily translate to a CBT construction, as does feedback, analysis, and automate grading through CBT, Due to the attraction of this choice, it is significant to extend the research on assessment method impact of CBT in all educational fields and discuss how variation in exam formats can influence on performance and enhance the attitudes towards CBT between examinees. 
Further studies are also needed regarding practice with CBT. Most of the existing studies compare assessments given on CBT and on CBT with restricted attempts. Based on students' ability and the use of technology in their classrooms, this might have been one of the few opportunities to use a computer for an assessment. A study that allows practice in the CBT format over time would give some idea about how practice may or may not change the difference in results based on format.

Along with this direction, future studies that focusing on rising computer and keyboarding skills would be worthy. Finally, additional research is needed with a wider domain of students' ages, gender, their levels of study, and grade level. Expanding research in such variables would allow for further in-depth researches in this trend.

\section{References}

1. Siozos, P., Palaigeorgiou, G., Triantafyllakos, G. and Despotakis, T. (2009) Computer Based

2. Testing Using "Digital Ink": Participatory Design of a Tablet PC Based Assessment Application for Secondary Education. Computers \& Education, 52, 811-819.

3. Shah, J. H. (2002). Validity and Credibility of Public Examinations in Pakistan. An Unpublished Thesis Submitted for the Degree of Ph. D., in the Department of Education, Islamic University Bahawalpur, Pakistan.

4. Havens, A. (2002). Examinations and Learning: An Activity - Theoretical Analysis of the Relationship between Assessment and Learning.

5. Rehmani, A. (2003). Impact of Public Examination System on Teaching and Learning in Pakistan. Retrieved December 24, 2010 from http://www.aku.edu/AKUEB/pdfs/pubexam.pdf.

6. Sim, G., Holifield, P., \& Brown, M. (2004). Implementation of Computer Assisted Assessment: Lessons from the Literature. ALT-J, Research in Learning Technology, 12 (3), 217 - 233.

7. Uysal, O. and Kuzu, A. (2009). A Thesis Proposal: Quality Standards of Online Higher Education in Turkey. Internationalization and the Role of University Networks. Proceedings of the 2009 EMUNI Conference on Higher Education and Research, Potorož, Sloveni.

8. McKenna, C. (2001). Introducing Computers into Assessment Process: What is the Impact upon Academic Practice? Paper Presented at Higher Education Close Up Conference 2, Lancaster University, and 16 - 18 July. Retrieved November 4, 2004 from http://leeds.ac.uk.

9. Lim, E., CH., Ong, B., KC. Wilder-Smith, E., PV. Seet, R., CS. (2006). Computer-based Versus Pen-and-paper Testing: Students' Perception. Ann Acad Med Singapore, 35 (9), 599-603.

10. Whittington, D., Bull, J., \& Danson M. (2000). Web-Based Assessment: Two UK Initiatives. The Sixth Australian World Wide Web Conference, Rihga Colonial Club Resort, Cairns, 12-17 June 2000, Australia.

11. Conole, G., \& Warburton, B. (2005). A Review of Computer Assisted Assessment. ALT-J, Research in Learning Technology, 13(1), 17-31.

12. Fluck, A., Pullen, D., and Harper, C., (2009). Case study of a computer based examination system. Australasian journal of Educational Technology, 25(4), 509- 523.

13. Powers, D.E. \& O'Neill, K. (1993).Inexperienced and anxious computer users: coping with a computeradministered test of academic skills. Education Assessment .1(2), 153-173.

14. Karadeniz, S. (2009). The impacts of paper, web and mobile based assessment on students' achievement and perceptions. Scientific Research and Essay, 4(10), 984 - 991. Retrieved May 15, 2011 from http:

//www.academicjournals.org/sre.

15. Leeson, H. (2006). The Mode Effect: A Literature Review of Human and Technological Issues in Computerized Testing. International Journal of Testing, 6(1), 1-24.

16. Yurdabakan, I. (2012). Primary School Students' Attitudes towards Computer Based testing and Assessment in Turkey. Turkish Online Journal of Distance Education- 13 (12), 177-188. 
17. Pomplun M., Ritchie, T., \& Custer M. (2006). Factors in paper-and-pencil and computer reading score differences at the primary grades. Educational Assessment, 11(2), 127-143.

18. Pomplun, M., \& Custer, M. (2005).The score comparability of computerized and paper-and-pencil formats for K-3 reading tests. Journal of Educational Computing Research, 32(2), 153-166.

19. Bennett, R. E. (2015). The Changing Nature of Educational Assessment. Review of Research in Education, 39(1), 370-407.

20. Bennett, R.E., Braswell, J., Oranje, A., Sandene, B., Kaplan, B., \& Yan, F. (2008). Does it matter if I take my mathematics test on computer? A second empirical study of mode effects in NAEP.Journal of Technology, Learning, and Assessment, 6(9) 1-39.

21. Gallagher, A., Bridgeman, B. \&Cahalan, C. (2002). The Effect of Computer- Based Tests on Racial-Ethnic and Gender Groups. Journal of Educational Measurement, 39(2), 133-147.

22. Terzis, V. and Economides, A.A. (2011) .the Acceptance and Use of Computer Based Assessment. Computers \& Education, 56, 1032-1044. http://dx.doi.org/10.1016/j.compedu.2010.11.017.

23. Williams, B. (2007). Students' perception of pre-hospital web-based examinations. International Journal of Education and Development using Information and Communication Technology, 3(1), 54-63.

24. Ozden, M.Y., Erturk, I., \& Sanli, R. (2004).Students' perception of online assessment: A case study. Journal of Distance Education. 19(2), 77-92.

25. Johnson, M. \& Green, S. (2004). On-line assessment: the impact of mode on students 'strategies, perceptions and behaviours.University of Cambridge.

26. Russell, M. \& O'connor, K. (2003).Computer-Based Testing and Validity: A look back and into the future. Lynch School of Education. InTASC publications.

27. McVay, R.B. (2002). An examination of computer anxiety related to achievement on paper-and-pencil and Computer-Based knowledge testing of United States air force technical training students. PhD Thesis. University of North Texas.

28. Millsap, C.M. (2000).Comparison of computer testing versus traditional paper and pencil testing. $\mathrm{PhD}$ Thesis. University of North Texas.

29. Pellegrino, J. W. \& Quellmalz, E. S. (2010). Perspectives on the integration of technology and assessment. Journal of Research on Technology in Education, 43(2). 119-134.

30. Kapoor, S., \& Welch, C. (2011, April). Comparability of paper and computer administrations in terms of proficiency interpretations. Paper presented at the 2011 Annual Meeting of the National Council on Measurement in Education, New Orleans, LA.

31. Poggio. J. \& McJunkin, L. (2012). History, current practice, perspectives and what the future holds for computer based assessment in K-12 education. In R. W. Lissitz \& H. Jiao (Eds.), Computers and their impact on state assessments (pp. 25-53). Charlotte.

32. Bodmann, S. M., \& Robinson, D. H. (2004). Speed and performance differences among computer-based and paper-pencil tests. Journal of Educational Computing Research, 31(1), 51-60.

33. Ripley, M. (2009). Transformational computer-based testing. In F. Scheurmann \& J. Bjornsson (Eds.), the Transition to Computer-Based Assessment (pp. 89-91). Luxembourg, Office for Official Publications of the European Communities.

34. Dean, V. \& Martineau, J. (2012). A state perspective on enhancing assessment and accountability systems through systematic implementation of technology. In R. W. Lissitz \& H. Jiao (Eds.), Computers and their impact on state assessments (pp. 25-53). Charlo.

35. Bridgeman, B. (2009). Experiences from large-scale computer-based testing in the USA. In F. Scheurmann \& J. Bjornsson (Eds.), the Transition to Computer-Based Assessment (pp. 39-44). Luxembourg, Office for Official Publications of the European Communities.

36. Darrell, L.B. (2003). The Impact of Computer-Based Testing on Student Attitudes and Behavior. The Technology Source. 
37. Fyfe, G., Meyer, J., Fyfe, S., Ziman, M., Sanders, K., \& Hill, J. (n.d). Self-evaluation of assessment performance can enhance student's perception of feedback on computer-generated tests.

38. Sorana-Daniela, B. \& Lorentz, J. (2007). Computer-based testing on physical chemistry topic: A case study. International Journal of Education and Development using Information and Communication Technology, 3(1), 94-95.

39. Terzis, V. and Economids, A. A. (2011). Computer based assessment: Gender differences in perceptions and acceptance, Computers in Human Behavior 27, 2108-2122.

40. KO, C.C. and Cheng, C.D. (2008) Flexible and Secure Computer-Based Assessment Using a Single Zip Disk. Computers and Education, 50, 915-926. http://dx.doi.org/10.1016/j.compedu.2006.09.010.

41. Gvozdenko, E., \& Chambers, D. (2007). Beyond test accuracy: Benefits of measuring response time in computerized testing. Australasian Journal of Educational Technology, 23(4), 542-558.

42. Saad, S.A. (2009). Computer-based testing vs. Paper-based testing: Establishing the comparability of Reading Tests through the Evolution of a New Comparability Model in a Saudi EFL context. PhD Thesis. University of Essex.

43. John, C.K., Cynthia, G.P., Judith, A.S., \&Tim, D. (2002). Practical Considerations in Computer-Based Testing. Sheridan Books. New Jersey: Lawrence Erlbaum Associates.

44. Jimoh, R. G., Abdul Jaleel Kehinde Shittu and Kawu, Yakub Kola.(2012). Students' Perception of Computer Based Test (CBT) for Examining Undergraduate Chemistry Courses. Journal of Emerging Trends in Computing and Information Sciences, Vol.3, No.2, pp: 125.

45. Russell, M. \& O'connor, K. (2003).Computer-Based Testing and Validity: A look back and into the future. Lynch School of Education. In TASC publications. 